\title{
The integration of ICT in creative multimedia in visual art education teaching and learning
}

\author{
Syamrul Nizam Abdul Malek*, Harozila Ramli, Ridzuan Hussin \\ Faculty of Art, Computing \& Creative Industry, Sultan Idris Education University, Tanjung Malim, Malaysia
}

\section{ARTICLE INFO}

\section{Article history:}

Received 7 July 2016

Received in revised form

20 October 2016

\section{Keywords:}

Integration

ICT

Visual art education

Teaching \& learning

Institute of teacher education
Accepted 5 November 2016

\begin{abstract}
A B S T R A C T
The objective of this study is to identify the Ely's Variation (Conditions of Change) - 1999, which exists to support the integration of ICT. The sample consists of VAE major students - semester 5, 6, 7 and 8, who have attended the course. As a result of the fish bowl draw for choosing the population capable of governance, a total of 223 VAE students from 6 ITE in Peninsular Malaysia have been selected for this study. The respondents come from these institutes: 1) IPGK Bahasa Antarabangsa (9.0\%), 2) IPGK Dato' Razali Ismail (9.0\%), 3) IPGK Raja Melewar (25.6\%), 4) IPGK Pendidikan Teknik $(9.9 \%), 5)$ IPGK Ilmu Khas (13.5\%) and 6) IPGK Sultan Mizan (33.2\%). From the $223(100 \%)$ sets of questionnaires distributed, 213 (96\%) sets have been successfully analysed. The study uses a questionnaire survey method. The questionnaires consist of 6 items (Demographic Information of Respondents) and 40 items (Ely terms, 1999). The reliability of the instruments for integrating ICT according to Ely's requirements is 0.86 . Data is analysed using Mean (M) and Standard Deviation (SD). The findings indicate the existence and support the integration of ICT through the T\&L process. The 7 conditions specified above are of varying stages. The third term, which is the Resources Readiness, obtained ( $M=2.37, \mathrm{SD}=0.73$ ), indicating that the existence of this condition is somewhat less supportive of the integration of ICT. It can be concluded that the VAE students thought that they did not have sufficient resources to enable them to integrate ICT through the T\&L process of Creative Multimedia in Visual Art Education courses in ITE.
\end{abstract}

(C) 2017 The Authors. Published by IASE. This is an open access article under the CC BY-NC-ND license (http://creativecommons.org/licenses/by-nc-nd/4.0/).

\section{Introduction}

On July 13, 2005, 27 Teacher Training Colleges

In the context of education in Malaysia, for the realization of Vision 2020, the government does not want to be left behind in the development of Information and Communication Technology (ICT). ICT is an enabler that is the backbone of the Teaching and Learning process (T\&L) and the school management. This represents a major challenge to the education sector in particular, which is to produce competitive teachers (Maulan and Ibrahim, 2012). The implementation of changes should be done immediately whether in the T\&L process or management. The effects of the various claims have brought major changes to the education sector in Malaysia.

\footnotetext{
* Corresponding Author.

Email Address: syammars76@yahoo.com (S. N. A. Malek)

https://doi.org/10.21833/ijaas.2017.04.019

2313-626X/C 2017 The Authors. Published by IASE.

This is an open access article under the CC BY-NC-ND license

(http://creativecommons.org/licenses/by-nc-nd/4.0/)
}

have been upgraded to Institute of Teacher Education to produce more graduate teachers and Malaysian Quality Framework has been used to ensure the quality of educators trained by Institute of Teacher Education (Umar and Jamiat, 2011). Teacher Education Division (TED) under the Ministry of Education (MOE) is responsible for the management of the teacher education programme "pre-service" and "in service" so that the National Education Philosophy and the Philosophy of Teacher Education are met in order to produce qualified teachers and to achieve the educational system of

Advances in ICT is growing rapidly and giving tremendous impact on the education in Malaysia today. ICT is one of the most important components of the T\&L in national education system in the 21st which involves learning pedagogy and ICT that must be generated in each coach. These skills are known as the $21^{\text {st }}$ century skills to prepare students for lives of significance and responsibility (by developing) a life of the mind for practice and to blend knowledge, world-class teachers. century. Among the skills are education knowledge 
skills, and appropriate attitude in response to unique situations that require expert judgment.

Indeed, the acceptance and awareness of the importance of ICT among VAE teachers is still low. Teacher education prioritize the formation of teachers whose dedication, creative, always trying and sensitive in enhancing professional skills and knowledge in the field of education to enable them to become agents effective in the process of human development and society as a whole and integrated. Trainee teachers, formerly known as trainees at the institute are prospective teachers who will serve in the future school. Training or applying computer and Internet courses may be required by teachers so that the computer can be used solely for the purposes of the T\&L process.

The lack of a comprehensive research conducted to determine the status of the integration of ICT in the process of T\&L in the Creative Multimedia in Visual Art Education courses among the VAE students at ITE has demonstrated the need for research related to the guidelines and description of the actions that should be implemented. Thus, researchers feel the need to make a survey of the course so as identify the conditions that will be encountered in the integration of ICT in order to produce VAE students in ITE pace with the progress and development of ICT in the $21^{\text {st }}$ century.

\subsection{Problem statement}

Interest in ICT can be seen covering the interests of a teacher trainer who is now known as trainee teachers in relation to some matters relating to the history of computers, how computers work, programming of computer programs, income courseware, assessment courseware commercial, computer applications for T\&L process, in computer data security and copyright law. All the things mentioned above are crucial if a person can be considered to have high skills in ICT. Therefore, teachers need to equip themselves with such things in earnest.

Curriculum modification from time to time also demands teacher educators should be more progressive to produce beginner teachers who are efficient technologically and confident to face challenges and have a strong commitment to the profession of work (Abet, 2009). In line with the development of innovative ICT in education, trainee teachers at the ITE should be ready to master ICT skills which includes proficiency using word processors, build electronic presentation, access the Internet, controlling the electronic media and use of computer networks for effective T\&L based ICT at a high level. However, the implementation process of the T\&L-based computers and ICT, is still poor as they find it among many trainee teachers at the Institute of Higher Education (IHE) difficult to master the skills of ICT and their competency is still at a low level.

Focusing on several aspects contained in the model of ICT skills among trainee teachers in the universities in Malaysia, in 11 universities with education programs such as Universiti Teknologi Mara (UTM), Universiti Teknologi Tun Hussein Onn Malaysia (UTTHOM), Universiti Putra Malaysia (UPM), Universiti Kebangsaan Malaysia (UKM), Universiti Malaya (UM), Universiti Teknologi Mara (UiTM), International Islamic University Malaysia (IIUM), Universiti Sains Malaysia (USM), Universiti Utara Malaysia (UUM), Universiti Malaysia Sabah (UMS) and Universiti Pendidikan Sultan Idris (UPSI), most teachers still emphasize less on aspects such as the integration of generic skills, self-access learning (self-acess), the rate of self (self-paced) and directed self (self-directed), various intelligence and learning styles, learning technology development and mastery of individual potential of ICT in T\&L process.

Evidence of past findings of various research have shown that the influence of the eight conditions of Model by Ely (1999) against the spread innovations in education in Malaysia reinforces this argument. It is equal to the findings of several research in the country.

However, researchers found that previous studies above are more likely to see the situation prevailing among trainee teachers in public institutions only, in the specialty field of Science and Mathematics, Humanities and Social Sciences and Technical and Vocational Education for Science, Mathematics, Bahasa Melayu, English, Engineering and Engineering. Thus, researchers feel the need to carry out a research to assess whether the existing conditions as stated in the Model Conditions of Change by Ely (1999) to the VAE students in the ITE in the integration of ICT through the T\&L process in Creative Multimedia Course in Visual Art Education. Eight conditions in the Model Conditions of Change by Ely that affect the acceptance of innovation in education namely; 1 . Dissatisfaction towards Status Quo, 2. Existing Knowledge and Skills, 3. Resource Readiness, 4. Time Readiness, 5. Reward or Incentive, 6. Involvement by all necessary parties, 7 . A Supportive Leadership, and 8. Commitment from all the parties involved (Ely, 1999).

\subsection{Research objective}

This research aims to identify the conditions that support the integration of ICT in the process of T\&L in the Creative Multimedia in Visual Art Education courses among the VAE students at ITE to answer the research questions that will be carried out based on the following objective:

Identify Ely (1999) conditions which exists to support the integration of ICT in the process of T\&L in the Creative Multimedia in Visual Art Education courses among the VAE students at ITE.

\subsection{Research question}

Based on the objectives of the research, the research question that are built are as follows: 
'What are the Ely (1999) conditions that exist and support the integration of ICT in the process of T\&L in the Creative Multimedia in Visual Art Education courses among the VAE students at ITE?'.

\section{Literature review}

ICT has contributed greatly to improving the quality of T\&L process on education in the 21st century. Many researchers have recognized the contribution of ICT to education. Most previous studies showed ICT not only is an enabler in various activities in the T\&L process in the classroom. According to Ely (1990) in the Model Rules Changes (Conditions of Change), there are eight conditions that affect the acceptance or rejection of an innovation. Eight of these conditions are 1. Dissatisfaction towards Status Quo, 2. Existing Knowledge and Skills, 3. Resource Readiness, 4. Time Readiness, 5. Reward or Incentive, 6 . Involvement by all necessary parties, 7. A Supportive Leadership, and 8. Commitment from all the parties involved. According to Ely, to ensure an acceptable innovation, the proposed eight conditions must be met first. Nonexistence of one of these conditions will affect the acceptance of innovation (Ely, 1990). Thus, in identifying various conditions or factors affecting the integration of ICT, eight conditions or factors produced by Ely highly suitable as indicators in this research.

Model Ely (1999) has gained the attention of many researchers and various studies have been conducted based on eight conditions. The findings from these studies have shown that the importance of the existence of all the conditions to ensure that innovation can be accepted and survive in a system. Based on the insights and conclusions from previous research, eight conditions proposed by Ely are to be used as a measuring tool in identifying strategies to be adopted to ensure the integration of ICT can be expanded and maintained in the education system in Malaysia.

Based on the research of the MOE in 2010, found that the use of ICT in schools is very limited. As many as $80 \%$ of teachers use ICT less than one hour a week. Only a third of the students said their teachers regularly use ICT. There are some studies that have shown a positive relationship between the use of computers to achieve some of which show the relevance of the negative and some are showing no such association (MOE, 2012). Although ICT is used in teaching, in most cases it has not skip the use of PowerPoint as a teaching tool. There is no evidence that ICT is used to promote creativity, problem solving and communication skills and critical thinking among students (MOE, 2012).

Blending ICT in the curriculum is one of the priorities in Wave 1, 2013-2015, which introduces basic ICT technology. Use of ICT in VAE is across the curriculum content itself. The use of ICT should be seen as an addition to the T\&L VAE or instructional technology effective in producing art digital visual genuine and of high quality and value added in the field of visual communication and not be seen as a tool for replacing the use of conventional (MOE, 2012). The computer is a tool that sits in line with traditional media such as paints, crayons, pencils and other. It has its own qualities and can be used to work simple and complex. And using the same computer also needs to be developed in line with traditional media. If the students do work in other ways, they will be able to choose the most appropriate medium to develop their ideas. The use of ICT as a teaching tool is increasing, there was a need to look at how ICT can affect VAE (Ertmer and Ottenbreit-Leftwich, 2010).

One case related to the use of ICT in VAE can be discussed with the changes in art teaching pedagogy is happening now, that awareness of "cultural citizenship in an era of global media". VAE has long been an area that received media and views that are different (Nompula, 2012). The integration of ICT as a tool for processing VAE is inevitable because of the graphic arts and design studies have been identified to be relevant to the culture and has been widely acknowledged. Normally, the integration of ICT can create image production and interpretation of those inside and outside the classroom that will build some cases of interest among the faculty of arts other than the application process technology for nextgeneration products.

\section{Methodology}

This research is a quantitative research with descriptive survey design. In this study, researchers tried to identify the existence of eight conditions that support the integration of ICT in the process of T\&L in the Creative Multimedia in Visual Art Education courses among the VAE students at ITE as suggested by model of Ely (1999).

The sample consisted of students of VAE, semester 5, 6, 7 and 8, who has studied Creative Multimedia Course in VAE at the ITE. The results of the draw fish bowl for choosing the population able governance, a total of $223 \mathrm{VAE}$ students of 6 ITE in Peninsular Malaysia has been selected for this research were 1) IPGK Bahasa Antarabangsa (9.0\%), 2) IPGK Dato' Razali Ismail (9.0\%), 3) IPGK Raja Melewar (25.6\%), 4) IPGK Pendidikan Teknik (9.9\%), 5) IPGK Ilmu Khas (13.5\%) and 6) IPGK Sultan Mizan (33.2\%). Out of 223 (100\%) questionnaires were distributed, 213 (96\%) questionnaires were successfully analyzed.

In this research the instrument used was a set of questionnaires. It is divided into two parts, Part A, Information Demographics Respondents, Section B, Condition supports the integration of ICT in the process of T\&L in the Creative Multimedia in Visual Art Education courses among the VAE students at ITE.

\section{Results}

Based on findings, were 64 (30.0\%) VAE students from IPGK Sultan Mizan, 57 (26.8\%) VAE students 
from IPGK Raja Melewar, 30 (14.1\%) VAE students from PGK Ilmu Khas, 22 (10.3\% ) VAE students from IPGK Pendidikan Teknik and the remaining 20 (9.4\%) VAE students of teachers from the IPGK Bahasa Antarabangsa and IPGK Dato 'Razali Ismail. Overall, $138(64.8 \%)$ of the respondents were female students while only $75(35.2 \%)$ of the respondents were males.

In terms of the highest academic credentials, found a total of 204 (95.8\%) have the Sijil Pelajaran Malaysia (SPM), and 9 (4.2\%) Sijil Tinggi Pelajaran Malaysia (STPM). For the results of the subject Visual Arts Education in the Sijil Pelajaran Malaysia, a total of $180(84.5 \%)$ had excellent results, 24 (11.3\%) scored distinctions, $5(2.3 \%)$ received a pass and the remaining $4(4 \%)$ had other results. Overall a total of 213 respondents $(100 \%)$ were major teacher education students of the Visual Art.

Table 1 shows that, 7 out of 8 of these conditions exist and support the integration of ICT in the process of T\&L in the Creative Multimedia in Visual Art Education courses among the VAE students at ITE as a mean value greater than 2.50. These conditions are:

1. Dissatisfaction towards Status Quo ( $M=2.95, \mathrm{SD}$ $=1.15$ ),

2. Existing Knowledge and Skills $(\mathrm{M}=3.80, \mathrm{SD}=$ 0.70 ),

3. Resource Readiness ( $\mathrm{M}=2.37, \mathrm{SD}=0.73$ )

4. Time Readiness $(M=3.28, S D=0.96)$,

5. Rewards or Incentive $(M=3.56, S D=0.94)$,

6. Involvement by all necessary parties $(\mathrm{M}=3.95$, $\mathrm{SD}=0.80$ ),

7. A Supportive Leadership ( $\mathrm{M}=3: 37, \mathrm{SP}=0.96)$ and

8. Commitment from all the parties involved $(\mathrm{M}=$ $3.81, \mathrm{SD}=0.82$ ).

Table 1: The existence of the variation (Condition of Change) in Creative Multimedia in Visual Art Education

\begin{tabular}{|c|c|c|c|}
\hline Number & Conditions & Mean & SD \\
\hline 1 & $\begin{array}{l}\text { Dissatisfaction towards } \\
\text { Status Quo }\end{array}$ & 2.95 & 1.15 \\
\hline 2 & $\begin{array}{l}\text { Existing Knowledge and } \\
\text { Skills }\end{array}$ & 3.80 & 0.70 \\
\hline 3 & Resource Readiness & 2.37 & 0.73 \\
\hline 4 & Time Readiness & 3.28 & 0.96 \\
\hline 5 & Reward or Incentive & 3.56 & 0.94 \\
\hline 6 & $\begin{array}{l}\text { Involvement by all } \\
\text { necessary parties }\end{array}$ & 3.95 & 0.80 \\
\hline 7 & A Supportive Leadership & 3.37 & 0.96 \\
\hline 8 & $\begin{array}{c}\text { Commitment from all the } \\
\text { parties involved }\end{array}$ & 3.81 & 0.82 \\
\hline
\end{tabular}

Results show that the existence and support the integration of ICT in the process of T\&L in the Creative Multimedia in Visual Art Education courses among the VAE students at ITE of the 7 conditions specified above are at varying stages. Terms of the 3rd of Resource Readiness obtained (Min 2:37, SD = 0.73 ), indicating that the existence of this condition is somewhat less supportive of the integration of ICT in the process of T\&L. Formulations that can be made is that the VAE students thought they did not have sufficient resources to enable them to integrate ICT in the process T\&L in the Creative Multimedia in Visual Art Education Course among the VAE students at ITE.

\section{Discussion}

Model of the Variation (Conditions of Change) Ely (1999) Exist to Support Integration of ICT for the research of 'What are the Ely (1999) conditions that exist and support the integration of ICT in the process of T\&L in the Creative Multimedia in Visual Art Education courses among the VAE students at ITE?'. The findings of this survey show that 7 out of 8 conditions proposed by Ely exist and support the integration of ICT in the process of T\&L in the Creative Multimedia in Visual Art Education courses among the VAE students at ITE. The 8 conditions are, 1. Dissatisfaction towards Status Quo, 2. Existing Knowledge and Skills, 4. Time Readiness, 5. Reward or Incentive, 6 . Involvement by all necessary parties 7. A Supportive Leadership, and 8. Commitment from all the parties involved.

The results of the research showed that $3^{\text {rd }}$ condition Ely namely Resource Readiness is moderate and the 7 other conditions were at varying rates.

A research was conducted by Nawawi (2005) to determine the presence or non-presence of any of the conditions proposed by Ely in facilitating the use of computers by 120 mathematics teachers in secondary schools in Malaysia. Research findings parallel studies in which he shows that all the Ely conditions exist and support the integration of ICT by teachers in the process of the T\&L. In addition, in another study by Nawawi (2005) to over 327 members of the Faculty of various academic disciplines found the main factor for not using a particular technology includes lack of facilities and resources (Nawawi, 2005). His findings are consistent with the findings of this research.

Parallels to the findings of this research, we can be attributed the various efforts taken by the MOE to improve the integration of ICT in the process of the T\&L. MOE continues to aim to qualify all to officially reach the level of Smart School of achieving a minimum standard of use, capacity, availability of ICT infrastructure and applications, in addition to integrating ICT in the process of the T\&L.

Malaysian Education Development Plan (20132025) has introduced basic ICT in Wave 1, 2013 2015. MOE will build ICT capacity on an existing. This effort is made to ensure basic ICT infrastructure and competence are always available in the system and are not tied to any particular technology platform. Preference is given including ensuring that teachers and students have sufficient access to ICT equipment, providing the education system with the learning platform and network bandwidth sufficient to use ICT services and ensure all teachers have basic competence in ICT. Other priorities in this period include improving the monitoring system in 
place to provide assessments more accurately on the progress of ICT initiatives, blending of ICT in the curriculum and provide quality content as well as cost-effective as measures to bridge the digital divide among teachers and students as a result of the rapid development of ICT.

\section{Conclusion}

Overall, the integration of ICT in the process of T\&L in the Creative Multimedia in Visual Art Education courses among the VAE students at ITE are in the medium level. The existence of the Variation (Conditions of Change) Ely (1999) is seen as being at a level that supports the integration efforts. However, as the view Ely argued for the existence of the eight conditions he proposes to ensure an acceptable and lasting innovation.

The 21st century requires a variety of skills to ensure the continuity of the ITE. $21^{\text {st }}$ century skills is a skill that must be mastered and practiced by lecturers and students to improve the quality of T\&L process in accordance with the current challenges and demands. For the dimensions of the ICT, the ITE should be competent in the use of ICT in the T\&L process, management, research and development. VAE students in teacher training institutes should be equipped with available resources to provide materials for their ready use of ICT for the purpose of the T\&L processes. So, the need of learning resources such as software, courseware, faster Wi-Fi connection system and Learning Module Courses should be enhanced so that the role ICT can be improved to the level of excellence in education in the next ITE education system in Malaysia.

\section{References}

Abet AA (2009). The commitment of visual art education teacher (minor) postgraduate teaching courses in the teaching of visual arts education in primary school. M.Sc. Thesis, Universiti Pendidikan Sultan Idris, Malaysia.

Ely DP (1990). Condition that facilitate the implementation of educational technology innovations. Journal of Research on Computing in Education, 23(2): 298-305.

Ely DP (1999). New perspectives on the implementation of educational technology innovations. ERIC Document Reproductive Service No. ED 427 775. Available online at: https://eric.ed.gov/?id=ED427775

Ertmer PA and Ottenbreit-Leftwich AT (2010). Teacher technology change: How knowledge, confidence, beliefs, and culture intersect. Journal of Research on Technology in Education, 42(3): 255-284.

Maulan SB and Ibrahim R (2012). The teaching and learning of English for academic purposes in blended environment. Procedia-Social and Behavioral Sciences, 67: 561-570.

MOE (2012). Preliminary Report Malaysia Education Blueprint 2013 - 2025. Ministry of Education, Kuala Lumpur, Malaysia, 27: 1-268.

Nawawi MH (2005). Condition facilitating utilizing of instructional technology in higher education: A study of Universiti Putra Malaysia, instructional design, development and evaluation. Ph.D. dissertation, Syracuse University, New York, USA.

Nompula Y (2012). An investigation of strategies for integrated learning experiences and instruction in the teaching of creative art subjects. South African Journal of Education, 32(3): 293-306.

Umar IN and Jamiat N (2011). Trends of ICT research in teaching education: An analysis of the Malaysian instructional technology proceedings. Asia Pacific Journal of Educators and Education, 26(1): 1-14. 